\title{
Uso de águas salinas como alternativa na irrigação e produção de forragem no semiárido nordestino ${ }^{1}$
}

\author{
José L. de A. Silva², José F. de Medeiros ${ }^{3}$, Samara S. V. Alves ${ }^{4}$, \\ Francisco de A. de Oliveira ${ }^{5}$, Manoel J. da Silva Junior ${ }^{6}$ \& Iarajane B. do Nascimento ${ }^{7}$ \\ ${ }^{1}$ Trabalho selecionado do II INOVAGRI International Meeting, realizado de 13 a 16 de abril de 2014, Fortaleza - CE, Brasil \\ ${ }^{2}$ DCAT/UFERSA. Mossoró, RN. E-mail: jose_leoncio100@yahoo.com.br \\ ${ }^{3}$ UFERSA. Mossoró, RN. E-mail: jfmedeir@ufersa.edu.br \\ ${ }^{4}$ DCV/UFERSA. Mossoró, RN. E-mail: agrosan29@hotmail.com \\ ${ }^{5}$ DCAT/UFERSA. Mossoró, RN. E-mail:thikaoamigao@ufersa.edu.br \\ ${ }^{6}$ DCAT/UFERSA. Mossoró, RN. E-mail:mjanuario@ufersa.edu.br (Autor correspondente) \\ DCAT/UFERSA. Mossoró, RN. E-mail: iarajane@hotmail.com
}

\section{Palavras-chave:}

Zea mays

Sorghum bicolor L. Moench

recursos hídricos

salinização

\begin{abstract}
R E S U M O
A produção de forragem no semiárido brasileiro é limitada, em virtude da variação da quantidade e qualidade da água, e ainda dos solos encontrados na região. Nesse contexto foi desenvolvido um experimento na Universidade Federal Rural do Semi-Árido - UFERSA, em Mossoró-RN. O delineamento experimental utilizado foi o inteiramente casualizado, em esquema fatorial $2 \times 3$, com três repetições. Os tratamentos resultaram da combinação de dois tipos de solos, um Argissolo Vermelho-Amarelo eutrófico (PVAe) e um Cambissolo Háplico Ta eutrófico (CXve), com

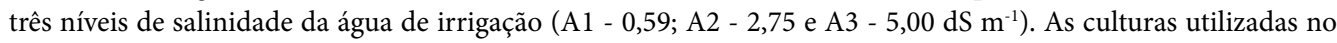
experimento foram milho e sorgo. As variáveis analisadas ao final do experimento foram: área foliar, matéria seca e teor de proteína bruta. A resposta das culturas à salinidade é dependente das características físicas do solo, sendo mais tolerantes em solo com menor teor de argila. A mistura de águas salinas possibilita a produção satisfatória de forragem sem reduzir o teor protéico. A mistura de águas até se obter condutividade elétrica de $2,75 \mathrm{dS} \mathrm{m}{ }^{-1}$ possibilita economia de $43,3 \%$ na água de boa qualidade, com perda de aproximadamente $22 \%$ na produção de biomassa.
\end{abstract}

Key words:

Zea mays

Sorghum bicolor L. Moench

water resources

salinization

\section{Use of saline waters as an alternative for irrigation and production of fodder in the northeastern semiarid region}

\begin{abstract}
A B S T R A C T
Forage production in the Brazilian semiarid region is limited due to water quantity and quality variation, and the soils of the region. In this context an experiment was conducted at the Federal Rural University of the Semi-Arid UFERSA in Mossoró-RN. The experimental design consisted of a completely randomized, factorial $2 \times 3$ with three replications. The treatments resulted from the combination of two types of soils and three levels of salinity of the irrigation water. The types of soil were Alfisol Red Yellow Eutrophic (PVAe) and Ta Eutrophic Cambisol (CXve), while the salinity levels were A1 - 0.59; A2 - 2.75 and A3 - $5.00 \mathrm{dS} \mathrm{m}^{-1}$. The crops used in the experiment were maize and sorghum. The variables analysed at the end of the experiment were: leaf area, dry matter and crude protein content. The crop response to salinity is dependent on the physical characteristics of the soil, being more tolerant in soil with lower clay content. The mixture of saline waters allows a satisfactory forage production without reducing the protein content. The mixture of water to obtain electrical conductivity of $2.75 \mathrm{dS} \mathrm{m}^{-1}$ allows $43.3 \%$ savings in water of good quality, with a loss of approximately $22 \%$ in biomass production.
\end{abstract}

\section{INTRODUÇÃO}

A escassez de água no mundo é agravada em virtude do crescimento populacional e da falta de manejo e usos sustentáveis dos recursos naturais. Segundo a UNICEF (Fundo das Nações Unidas para a Infância), menos da metade da população mundial tem acesso à água potável, as diferenças registradas entre os países desenvolvidos e os em desenvolvimento chocam e evidenciam que a crise mundial dos recursos hídricos está diretamente ligada às desigualdades sociais (SETESB, 2013). As maiores destinações de águas são para irrigação que corresponde a $73 \%$ do consumo de água, $21 \%$ vão para a indústria e apenas $6 \%$ destina-se ao consumo doméstico. De acordo com os números apresentados pela Organização das Nações Unidas (ONU), fica claro que controlar o uso da água significa deter poder.

No Brasil, a escassez desse recurso é bastante visível, sobretudo na região semiárida do Nordeste que corresponde a 58\% do território. A água utilizada na irrigação nessa região apresenta em grande parte alto teor de sais, tanto em águas 
superficiais como subterrâneas como nos açudes de pequeno e médio porte (superficiais) e poços (água subterrâneas) (Medeiros et al., 2003). Além disso, a disponibilidade da água para consumo humano e para a prática agrícola vem sendo gradativamente reduzida tanto em qualidade como em quantidade, fazendo assim necessário o uso alternativo de água de qualidade inferior para atender a demanda da irrigação agrícola nessas regiões.

Uma das alternativas para o uso dessas águas de elevadas salinidades é a sua mistura com água de baixa concentração de sais, sendo este um manejo estratégico, para incentivar a inserção dessas águas na produção vegetal em regiões que sofrem com estiagens prolongadas. Esta pode ser mais uma alternativa para assegurar a exploração racional dos recursos hídricos e vegetais no semiárido, fixando o homem no campo evitando o êxodo rural.

A técnica de mistura de águas pode permitir a irrigação de áreas maiores, mas não diminui o total dos sais nas águas de irrigação. Em muitas áreas irrigadas do mundo, o suprimento de água de boa qualidade pode não ser suficiente para a manutenção da agricultura irrigada, buscando-se alternativas com o uso de água do lençol freático ou mesmo de drenagem. Todavia, geralmente, essas águas não são de boa qualidade e uma das alternativas para viabilizar seu uso é misturá-las com água de baixa concentração de sais (Mendes et al., 2008).

A região do semiárido nordestino, apesar de apresentar irregularidades climáticas, destaca-se nacionalmente no setor pecuário, principalmente na ovinocaprinocultura. Entretanto, o êxito desse setor é dependente diretamente da disponibilidade de alimento de qualidade, a qual pode ser adquirida a partir do uso de irrigação na produção de forragem.

As culturas do milho e do sorgo vêm ocupando lugar de destaque na região Nordeste, pelas suas elevadas produtividades mesmo quando irrigadas com água de elevada salinidade e podem se constituir em alternativas para cultivos que utilizem recursos (água e solo) salinos (Morais Neto, 2009).

Nesse contexto, torna-se importante estudar o uso de águas salinas como alternativa para a irrigação de forragem no semiárido brasileiro. A abordagem é baseada na integração de estratégias, soluções e desafio para a utilização de misturas de águas para irrigação de culturas tradicionalmente utilizadas em regiões mais afetadas, tendo por base os princípios de sustentabilidade. Diante do exposto, objetivou-se avaliar o uso de águas salina na cultura de sorgo e milho, cultivados em dois tipos de solos.

\section{Material e Métodos}

O experimento foi realizado no período de outubro a dezembro 2010, em casa de vegetação na Universidade Federal
Rural do Semi-Árido - UFERSA, do Departamento de Ciências Ambientais e Tecnológicas-DCAT, localizada no município de Mossoró, RN, com as coordenadas geográficas de $5^{\circ} 11^{\prime} 31^{\prime \prime}$ latitude Sul e $37^{\circ} 20^{\prime} 40^{\prime \prime}$ de longitude Oeste e altitude média de $18 \mathrm{~m}$.

O clima dominante da região, de acordo com a classificação de Köppen, é do tipo BSwh', ou seja, quente e seco caracterizando como clima tropical Semiárido, com estação chuvosa bastante irregular, atrasando-se do verão para o outono, se concentrando nos primeiros meses do ano. De acordo com Carmo Filho \& Oliveira (1989), as características climáticas do local são: temperatura média de $27,4^{\circ} \mathrm{C}$, precipitação pluviométrica média anual de 673,9 mm e umidade relativa do ar de 68,9\%.

As culturas utilizadas no experimento foram milho e sorgo, sendo escolhidas por serem as mais utilizadas pelos produtores rurais e apresentarem área de cultivo em expansão na região, como também pela falta de informações técnicas obtidas para a região, principalmente quanto à tolerância a salinidade, além de possuírem boa adaptação às condições climáticas da região.

O delineamento experimental utilizado foi o inteiramente casualizado, arranjados em esquema fatorial $2 \times 3$, com três repetições, sendo a unidade experimental representada por uma coluna de PVC com capacidade para $12 \mathrm{~L}$, contendo uma planta em cada coluna.

Os tratamentos resultaram da combinação de dois tipos de dois solos: um Argissolo Vermelho-Amarelo Eutrófico (PVAe) e um Cambissolo Háplico Ta Eutrófico (CXve), com três níveis de salinidade da água de irrigação (A1 - 0,59; A2 - 2,75 e A3 $5,00 \mathrm{dS} \mathrm{m}^{-1}$ ). A água de maior salinidade utilizada para irrigação foi coletada em poço que explora o aquífero Jandaíra (AJ) de origem calcária, com salinidade média de $5,56 \mathrm{dS} \mathrm{m}^{-1}$ enquanto a outra foi de abastecimento urbano (AU), com salinidade em torno de $0,59 \mathrm{dS} \mathrm{m}^{-1}$ (Tabela 1 ).

Para a determinação do volume de água de cada fonte para obtenção dos níveis salinos utilizados neste experimento, foi utilizada a Eq. 1 (Lacerda et al., 2010).

$$
\mathrm{CE}_{\mathrm{af}}=\frac{\left(\mathrm{CE}_{\mathrm{a} 1} \cdot \mathrm{V}_{\mathrm{a} 1}\right)}{\left(\mathrm{V}_{\mathrm{a} 1+\mathrm{a} 2}\right)}+\frac{\left(\mathrm{CE}_{\mathrm{a} 2} \cdot \mathrm{V}_{\mathrm{a} 2}\right)}{\left(\mathrm{V}_{\mathrm{a} 1+\mathrm{a} 2}\right)}
$$

em que:

$\mathrm{CE}_{\mathrm{af}}$ - CE final da mistura, $\mathrm{dS} \mathrm{m}^{-1}$

$\mathrm{CE}_{\mathrm{a} 1}$ - $\mathrm{CE}$ da água de menor salinidade, $\mathrm{dS} \mathrm{m}^{-1}$

$\mathrm{CE}_{\mathrm{a} 2}$ - CE da água de maior salinidade, $\mathrm{dS} \mathrm{m}^{-1}$

$\mathrm{V}_{\mathrm{a} 1}$ - volume da água de menor salinidade

$\mathrm{V}_{\mathrm{a} 2}$ - volume da água de maior salinidade

$\mathrm{V}_{\mathrm{a} 1+\mathrm{a} 2}$ - volume final da mistura

$\mathrm{V}_{\mathrm{a} 1} / \mathrm{V}_{\mathrm{a} 1+\mathrm{a} 2}$ - representa a proporção da água de menor salinidade $\left(\mathrm{P}_{\mathrm{a} 1}\right)$

Tabela 1. Composição química das águas, obtidas após a mistura, utilizadas no Experimento

\begin{tabular}{|c|c|c|c|c|c|c|c|c|c|c|}
\hline \multirow{2}{*}{ Água } & \multirow{2}{*}{$\begin{array}{c}C E \\
\left(\mathrm{dS} \mathrm{m}^{-1}\right)\end{array}$} & \multirow{2}{*}{$\mathrm{pH}$} & $\mathrm{Ca}$ & $\mathrm{Mg}$ & $\mathrm{Na}$ & $\bar{K}$ & $\mathrm{CO}_{3}$ & $\mathrm{HCO}_{3}$ & $\mathrm{Cl}$ & $\mathrm{SO}_{4}$ \\
\hline & & & \multicolumn{8}{|c|}{$\left(\mathrm{mmol}_{\mathrm{c}} \mathrm{L}^{-1}\right)$} \\
\hline A1 & 0,59 & 8,30 & 0,90 & 0,70 & 3,92 & 0,22 & 0,00 & 4,50 & 3,00 & Ausente \\
\hline $\mathrm{A} 2$ & 2,75 & 7,26 & 8,10 & 7,70 & 14,75 & 0,58 & 0,60 & 3,30 & 13,20 & Presente \\
\hline A3 & 5,00 & 8,40 & 19,80 & 22,20 & 24,96 & 1,01 & 0,00 & 3,90 & 22,40 & Presente \\
\hline
\end{tabular}


$\mathrm{V}_{\mathrm{a} 2} / \mathrm{V}_{\mathrm{a} 1+\mathrm{a} 2}$ - representa a proporção da água de maior salinidade $\left(\mathrm{P}_{\mathrm{a} 2}\right)$

A partir da equação acima determinou-se os volumes de água de cada fonte, obtendo-se as seguintes proporções: $\mathrm{CE}=0,59 \mathrm{dS} \mathrm{m} \mathrm{m}^{-1}(\mathrm{AU}-100 \% / \mathrm{AJ}-0 \%) ; \mathrm{CE}=2,75 \mathrm{dS} \mathrm{m}^{-1}(\mathrm{AU}-$ $56,5 \% / \mathrm{AJ}-43,5 \%)$; $\mathrm{CE}=5,00 \mathrm{dS} \mathrm{m}^{-1}(\mathrm{AU}-11,3 \% / \mathrm{AJ}-88,7 \%)$.

Os solos foram coletados nas profundidades de 0-20 e 20-40 $\mathrm{cm}$, secos ao ar, peneirados com peneira de $2 \mathrm{~mm}$ e distribuídos em colunas de PVC com $50 \mathrm{~cm}$ de altura e $20 \mathrm{~cm}$ de diâmetro. Utilizou-se uma camada de brita de $3 \mathrm{~cm}$ e manta geotêxtil "Bidim", como dreno e uma torneira para drenagem da água. $\mathrm{O}$ acondicionado das amostras do material de solo nas colunas foi feito de forma a representar as condições reais de campo em relação à densidade e respectivas profundidades.

Antes do plantio das culturas realizou-se adubação, determinada de acordo com análise previa dos solos e a exigência nutricional das culturas (Tabela 2). Realizou-se adubação de fundação, aplicando 4,15 g de P2O5 para cada coluna de solo, e, semanalmente foram realizadas adubações via fertirrigação com $\mathrm{N}$ e K de acordo com a necessidade das culturas, aplicando, por coluna de solo, um total de 5,0 g de $\mathrm{N}$ e 7,0 g de $\mathrm{K}_{2} \mathrm{O}$.

As variáveis analisadas foram: área foliar, matéria seca e teor de proteína bruta. A área foliar foi obtida a partir de análise feita semanalmente, medindo-se comprimento e a maior largura de todas as folhas de cada planta e estimadas a partir de Eq. 2.

$$
\mathrm{AF}=0,747 \times \mathrm{C} \times \mathrm{L}
$$

onde:

$$
\begin{aligned}
& \mathrm{AF} \text { - área da folha, } \mathrm{cm}^{2} \\
& \mathrm{C} \text { - comprimento da folha, } \mathrm{cm} \\
& \mathrm{L} \text { - maior largura da folha, } \mathrm{cm} \\
& \text { 0,747 - fator de correção }
\end{aligned}
$$

$\mathrm{Na}$ final do experimento, a área foliar foi estimada pelo método do disco, o qual consiste na retirada de discos foliares de área conhecida em quatro posições do limbo foliar de um conjunto de folhas, distribuídas simetricamente, evitando-se a amostragem da nervura central.

As folhas das plantas foram secas em estufa de circulação forçada com temperatura entre 65 e $70{ }^{\circ} \mathrm{C}$ até peso constante. Após a secagem o material obtido foi pesado em balança de precisão $(0,01 \mathrm{~g})$. Para a massa seca da parte aérea das plantas foi obtida a partir da soma da massa seca de folhas e colmo, sendo posteriormente moídas as folhas para as determinações de nitrogênio.

O procedimento utilizado para a determinação de proteína foi realizado através conversão de nitrogênio (Cecchi, 2003). $\mathrm{O}$ método utilizado para dosagem de proteínas foi proposto por Kjeldahl. Este método determina o $\mathrm{N}$, e para converter o nitrogênio medido em proteína, multiplica-se o conteúdo de nitrogênio por um fator geral que é obtido com base no fato de que, na maioria das proteínas, o teor de $\mathrm{N}$ é em torno de $16 \%$. Então: multiplicando-se por 6,25.

Os dados obtidos foram submetidos à análise de variância e teste de médias com auxílio do software SAEG 9.0 (Ribeiro Junior, 2001) e ajustes de equações de regressão usando o Excel.

\section{Resultados e Discussão}

De acordo com a análise de variância (Tabela 3), verificouse interação significativa entre os fatores salinidade e tipos de solo apenas para as variáveis área foliar do milho e matéria seca do sorgo ( $p<0,01)$. Entretanto, houve efeito significativo dos tipos de solo para a matéria seca $(\mathrm{p}<0,05)$ e proteína $(\mathrm{p}<0,01)$ do milho, bem como para área foliar, matéria seca e proteína do sorgo $(\mathrm{p}<0,01)$. Com relação à salinidade, observou efeito significativo para matéria seca e área foliar do milho e sorgo, não ocorrendo resposta significativa para o teor de proteínas $(\mathrm{p}>0,05)$.

O desdobramento da interação ( $\mathrm{x}$ SAL) para a área foliar

\begin{tabular}{|c|c|c|c|c|c|c|c|c|c|}
\hline \multirow{2}{*}{ Solos } & \multirow{2}{*}{$\mathrm{pH}$} & \multirow{2}{*}{$\begin{array}{c}\mathrm{MO} \\
\left(\mathrm{g} \mathrm{kg}^{-1}\right)\end{array}$} & $\mathbf{P}$ & $\bar{K}$ & $\mathrm{Ca}$ & $\mathrm{Mg}$ & $\mathrm{H}+\mathrm{Al}$ & CTC & \multirow{2}{*}{$\begin{array}{c}V \\
(\%)\end{array}$} \\
\hline & & & \multicolumn{2}{|c|}{$\left(\mathrm{mg} \mathrm{dm}^{-3}\right)$} & \multicolumn{4}{|c|}{$\left(\mathrm{cmol}_{\mathrm{c}} \mathrm{dm}^{-3}\right)$} & \\
\hline PVAe $(0-20 \mathrm{~cm})$ & 6,6 & 1,9 & 9,0 & 40,6 & 1,8 & 0,4 & 0,17 & 2,73 & 94 \\
\hline PVAe $(20-40 \mathrm{~cm})$ & 6,5 & 2,7 & 3,7 & 286,2 & 1,8 & 1,3 & 0,17 & 4,05 & 96 \\
\hline CXve $(0-20 \mathrm{~cm})$ & 6,7 & 8,0 & 3,6 & 145,6 & 8,7 & 1,0 & 1,16 & 11,58 & 90 \\
\hline CXve $(20-40 \mathrm{~cm})$ & 6,6 & 4,0 & 3,7 & 51,5 & 6,3 & 1,4 & 1,32 & 9,19 & 86 \\
\hline
\end{tabular}
(AF) do milho revela que no solo Argissolo Vermelho Amarelo - PVAe, os maiores valores foram observados nos níveis de salinidade 0,59 e $2,75 \mathrm{dS} \mathrm{m}^{-1}$ e os menores valores no nível de

Tabela 2. Características químicas dos solos utilizados no experimento

\begin{tabular}{|c|c|c|c|c|c|c|c|}
\hline \multirow{3}{*}{ FV } & \multirow{3}{*}{ GL } & \multicolumn{6}{|c|}{ Quadrado médio } \\
\hline & & \multicolumn{3}{|c|}{ Milho } & \multicolumn{3}{|c|}{ Sorgo } \\
\hline & & AF & MS & PB & AF & MS & PB \\
\hline Solo (S) & 1 & $0,02^{* *}$ & $4,763^{*}$ & $35,67^{* *}$ & $24,1^{\star \star}$ & $29,207^{* *}$ & $18,74^{* *}$ \\
\hline Salinidade (SAL) & 2 & $45,29 * *$ & $22,663^{\star *}$ & $1,042^{\text {ns }}$ & 3,26 * & $84,125^{\star *}$ & $2,15^{\mathrm{ns}}$ \\
\hline$S \times S A L$ & 2 & $9,48^{* *}$ & $3,262^{\mathrm{ns}}$ & $0,206^{\text {ns }}$ & $0,48^{\text {ns }}$ & $18,35^{\star \star}$ & $2,56^{\mathrm{ns}}$ \\
\hline CV (\%) & & 4,1 & 9,790 & 6,81 & 18,4 & 5,789 & 4,82 \\
\hline
\end{tabular}

Tabela 3. Resumo da analise de variância: área foliar (AF), massa seca da planta (MS) e proteína bruta (PB) nas culturas de milho e do sorgo sob estresse salino nos solos Argissolo Vermelho-Amarelo Eutrófico (PVAe) e Cambissolo Háplico Ta Eutrófico (CXve)

${ }^{\star *}$ significativo a 0,01 de probabilidade, ${ }^{*}$ significativo a 0,05 de probabilidade e ns não significativo 
5,00 dS m-1. Para o solo Cambissolo Háplico - CXve, houve redução na AF a partir da salinidade de $2,75 \mathrm{dS} \mathrm{m}^{-1}$ (Tabela 4).

Essa divergência entre os tipos de solos ocorreu provavelmente em decorrência das características físicas dos solos, pois o PVAe apresenta maior drenabilidade em consequência do maior teor de areia, o que facilita a lixiviação dos sais.

Ainda na Tabela 4, verifica-se que as plantas cultivadas no solo PVAe apresentou valor de AF superior ao valor observado no solo CXve, para a salinidade $2,75 \mathrm{dS} \mathrm{m}^{-1}$; enquanto que na maior salinidade $\left(5,00 \mathrm{dS} \mathrm{m}^{-1}\right)$ os maiores valores tendem a ser no solo CXve, embora não sejam estatisticamente diferentes.

Tabela 4. Valores médios ${ }^{\#}$ de área foliar $\left(\mathrm{cm}^{2}\right.$ planta $\left.^{-1}\right)$ da cultura do milho sob estresse salino em solos Argissolo Vermelho-Amarelo Eutrófico (PVAe) e um Cambissolo Háplico Ta Eutrófico (CXve)

\begin{tabular}{cccc}
\hline \multirow{2}{*}{ Solo } & \multicolumn{3}{c}{ CE água de irrigação ${\text { (dS } \mathbf{~ m}^{-1} \text { ) }}$} \\
\cline { 2 - 4 } & $\mathbf{0 , 5 9}$ & $\mathbf{2 , 7 5}$ & $\mathbf{5 , 0 0}$ \\
PVAe & $877,54 \mathrm{Aa}$ & $885,1 \mathrm{Aa}$ & $747,86 \mathrm{Bb}$ \\
CXve & $907,13 \mathrm{Aa}$ & $819,9 \mathrm{Bb}$ & $788,22 \mathrm{Ba}$ \\
\hline
\end{tabular}

\#Medias seguidos pela mesma letra maiúscula na linha e minúscula na coluna não diferem entre si pelo teste de Tukey a 0,05 de probabilidade

Para a cultura do sorgo, verificou-se que os maiores valores de área foliar ocorreram no solo CXve $\left(1159,42 \mathrm{~cm}^{2}\right.$ planta $\left.^{-1}\right)$, sendo superior em aproximadamente $31,2 \%$ em relação ao valor obtido no PVAe, que obteve-se área foliar de $883,74 \mathrm{~cm}^{2}$ planta $^{-1}$ (Tabela 5).

Com relação ao efeito da salinidade sobre a área foliar do sorgo, verificou-se que os maiores valores ocorreram nas plantas irrigadas com água de salinidade $0,59 \mathrm{dS} \mathrm{m}^{-1}\left(1108,1 \mathrm{~cm}^{2}\right.$ planta-1), e que o aumento da condutividade elétrica da água acima de 2,75 provocou decréscimo significativo desta variável (Tabela 5).

Analisado as duas culturas em conjunto, na maior salinidade, verificou-se perdas relativas de aproximadamente 13,1 e $14,8 \%$ na cultura do milho, para os solos PVAe e CXve, respectivamente; enquanto para a cultura do sorgo apresentou perda relativa de $15,8 \%$.

Outros pesquisadores também relataram efeito negativo da salinidade sobre o desenvolvimento foliar das culturas do milho (Lima et al., 2011; Sousa et al., 2012) e do sorgo (Lacerda et al., 2006; Feijão et al., 2011). A área foliar é uma das variáveis de crescimento vegetal mais afetado pela salinidade, pois sob estresse salino as plantas apresentam redução na transpiração

Tabela 5. Valores médios ${ }^{\#}$ de área foliar da cultura do sorgo sob solos Argissolo Vermelho-Amarelo Eutrófico (PVAe) e um Cambissolo Háplico Ta Eutrófico (CXve) e condutividade elétrica da água de irrigação

\begin{tabular}{cc}
\hline FV & Área foliar $\left(\mathbf{c m}^{2}\right.$ planta $\left.^{-1}\right)$ \\
Solo & \\
PVAe & $883,74 \mathrm{~b}$ \\
CXve & $1.159,42 \mathrm{a}$ \\
\hline CE da água de irrigação $\left(\mathrm{dS} \mathrm{m}^{-1}\right)$ & \\
0,59 & $1.108,1 \mathrm{a}$ \\
2,75 & $1.024,2 \mathrm{ab}$ \\
5,00 & $932,5 \mathrm{~b}$ \\
\hline
\end{tabular}

\#Medias seguidos pela mesma letra não diferem entre si pelo teste de Tukey a 0,05 de probabilidade e na taxa de assimilação líquida de $\mathrm{CO}_{2}$ provocada pelo fechamento dos estômatos em resposta ao baixo potencial da água do solo devido à elevada concentração salina.

A redução no crescimento foliar representa um mecanismo de defesa das plantas sob condições de estresse hídrico e salino, reduzindo as perdas de água por transpiração (Taiz \& Zeiger, 2009).

Na Figura 1 é apresentado o desenvolvimento foliar das culturas do milho e do sorgo durante o estudo, na qual se pode observar que ambas as culturas apresentaram crescimento exponencial, entretanto, houve divergência em relação ao efeito da salinidade ao longo do período experimental (40 dias).

Na cultura do milho foi observado que a resposta à salinidade ocorreu a partir dos 33 dias após a emergência, com maiores valores de $\mathrm{AF}$ ocorrendo nas menores salinidades (Figura 1A); Já para a cultura do sorgo não houve diferenciação quanto ao efeito da salinidade nas épocas de avaliação (Figura 1B).

Com relação à massa seca da parte aérea na cultura do milho, verificou-se que os maiores valores foram obtidos para o solo PVAe (5,34 tha $\left.\mathrm{t}^{-1}\right)$, enquanto que para as plantas cultivadas no solo CXve obteve-se massa seca de 4,83 tha (Tabela 6).

Quanto ao efeito da salinidade sobre a massa seca do milho, foi observado que os maiores valores ocorreram na salinidade de $0,59 \mathrm{dS} \mathrm{m}^{-1}\left(6,15 \mathrm{tha}^{-1}\right)$, e que a partir da salinidade de $2,75 \mathrm{dS} \mathrm{m}^{-1}$ ocorreu redução significativa nesta variável, ocorrendo redução

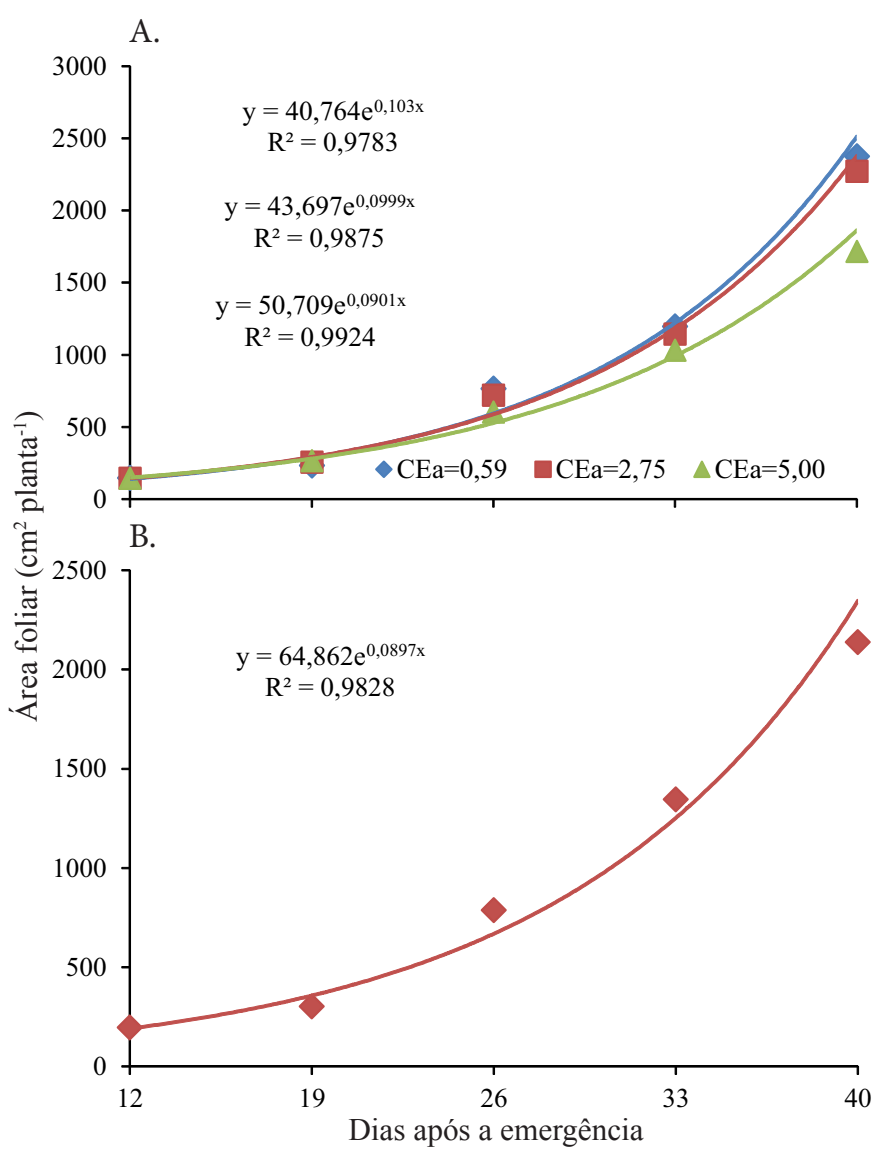

Figura 1. Evolução da área foliar nas culturas do milho (A) em função da salinidade da água de irrigação e do sorgo (B) durante o período experimental 
Tabela 6. Valores médios" de massa seca da parte aérea da cultura do milho sob solos Argissolo Vermelho-Amarelo Eutrófico (PVAe) e um Cambissolo Háplico Ta Eutrófico (CXve) e condutividade elétrica da água de irrigação

\begin{tabular}{cc}
\hline FV & Área foliar $\left(\mathbf{c m}^{2}\right.$ planta-1) \\
Solo & \\
PVAe & $5,34 \mathrm{a}$ \\
CXve & $4,83 \mathrm{~b}$ \\
\hline CE da água de irrigação $\left(\mathrm{dS} \mathrm{m}^{-1}\right)$ & \\
0,59 & $6,15 \mathrm{a}$ \\
2,75 & $4,82 \mathrm{~b}$ \\
5,00 & $4,27 \mathrm{~b}$ \\
\hline
\end{tabular}

\#Medias seguidos pela mesma letra não diferem entre si pelo teste de Tukey a 0,05 de probabilidade

de $21,6 \%$. No entanto, não houve diferença significativa entre as salinidades 2,75 e $5,00 \mathrm{dS} \mathrm{m}^{-1}$, apesar de ter ocorrido diferença absoluta entre estas salinidades de $0,55 \mathrm{t} \mathrm{ha}^{-1}(11,4 \%)$ (Tabela 6 ).

$\mathrm{Na}$ Tabela 7 é apresentada a produção de massa seca da parte aérea em plantas de sorgo, na qual se verifica que não houve diferença entre os tipos de solo quando as plantas foram irrigadas com água menos salina $\left(0,59 \mathrm{dS} \mathrm{m}^{-1}\right)$; no entanto, quando se utilizou águas salinas $\left(2,75\right.$ e 5,00 $\left.\mathrm{dS} \mathrm{m}^{-1}\right)$ os maiores valores ocorreram nas plantas cultivas no solo PVAe.

Com relação ao efeito da salinidade, verificou-se que nas plantas cultivadas no solo PVAe houve redução apenas na maior salinidade (5,00 dS m-1), apresentando redução de 23,8 e 18,3\% em comparação com as plantas irrigadas com água de menor salinidade. Para as plantas cultivadas no solo CXve, houve resposta significativa a partir da salinidade $2,75 \mathrm{dS} \mathrm{m}^{-1}$, com redução de $36,9 \%$ em relação à salinidade $0,59 \mathrm{dS} \mathrm{m}^{-1}$, alcançando perdas de $44,6 \%$ nas plantas submetidas à irrigação com água de condutividade elétrica de 5,00 $\mathrm{dS} \mathrm{m}^{-1}$ (Tabela 7).

Estes resultados demonstram que o solo PVAe proporcionou melhores condições de desenvolvimento das plantas, provavelmente por apresentar maior capacidade para drenagem e maior eficiência de lixiviação, permitindo o uso de água mais salina sem resultar em perdas significativas na produção de massa seca.

Comportamento semelhante foi observada por Silva et al. (2008) trabalhando com a cultura do meloeiro sob estresse salino e em quatro tipos de solos, dentre estes o PVAe e o CXve, os quais constataram maiores perdas de massa seca em resposta à salinidade, em plantas cultivadas no Cambissolo. Tal efeito ocorre porque os Cambissolos apresentam maior teor de argila de atividade alta, sendo assim mais susceptíveis aos processos de salinização e sodificação (Freire et al., 2003).

Tabela 7. Valores médios ${ }^{\sharp}$ de massa seca da parte aérea da cultura do sorgo sob estresse salino em solos Argissolo Vermelho-Amarelo Eutrófico (PVAe) e um Cambissolo Háplico Ta Eutrófico (CXve)

\begin{tabular}{cccc}
\hline \multirow{2}{*}{ Solo } & \multicolumn{3}{c}{ CE água de irrigação (dS $\mathbf{~ m}^{-1}$ ) } \\
\cline { 2 - 4 } & $\mathbf{0 , 5 9}$ & $\mathbf{2 , 7 5}$ & $\mathbf{5 , 0 0}$ \\
PVAe & $5,49 \mathrm{aA}$ & $5,12 \mathrm{aA}$ & $4,18 \mathrm{aB}$ \\
CXve & $5,83 \mathrm{aA}$ & $3,68 \mathrm{bB}$ & $3,23 \mathrm{bB}$ \\
\hline
\end{tabular}

\#Medias seguidos pela mesma letra maiúscula na linha e minúscula na coluna não diferem entre si pelo teste de Tukey a 0,05 de probabilidade
A partir dos resultados obtidos neste trabalho, constata-se que a tolerância à água salina depende da cultura e do tipo de solo utilizado, pois ao analisar a perda relativa de massa seca nas duas culturas entre os níveis extremos de salinidade $(0,59$ e $\left.5,00 \mathrm{dS} \mathrm{m}^{-1}\right)$, verificou-se que o milho apresentou redução total de $30,6 \%$ enquanto a cultura do sorgo apresentou redução total de 23,8 e 44,6\% de massa seca quando cultivado nos solos PVAe e CXve, respectivamente.

Apesar das culturas do milho e do sorgo serem classificadas como moderadamente tolerantes à estresse salino, vários estudos já demonstraram reduções significativas na produção de massa seca em reposta à salinidade, com taxas de perdas variando em função de materiais genéticos e condições ambientes (Lima et al., 2011; Sousa et al., 2012; Lacerda et al., 2006; Aquino et al., 2007; Feijão et al., 2011; Coelho et al., 2014).

O efeito negativo da salinidade sobre o desenvolvimento das plantas ocorre devido a diminuição da disponibilidade hídrica no solo, ocasionando queda no potencial da água da folha, levando à perda de turgescência e ao fechamento estomático, $\mathrm{o}$ que vai acarretar alterações na produção de biomassa (Munns $\&$ Tester, 2008)

O teor de proteína na matéria seca não foi influenciado pela salinidade da água de irrigação, obtendo-se teores médios de $13,34 \%$ para o milho e $13,17 \%$ para o sorgo, ocorrendo apenas efeito isolado do tipo de solo. As plantas de sorgo e milho cultivadas no solo Argissolo Vermelho-Amarelo (PVAe) apresentaram maiores teores de proteína bruta, obtendo-se 14,62 e 13,82\%, para milho e sorgo, respectivamente (Figura 2).

Apesar de não se ter observado efeito significativo da resposta sobre o teor de proteína, a superioridade do solo PVAe pode ser explicada, em parte, pela maior facilidade de lixiviação proporcionada por este solo, reduzindo o acúmulo de sais na zona radicular.

Neste contexto, outros autores observaram efeito deletério da salinidade sobre o crescimento e teor de proteína em plantas de sorgo, a exemplo de Vieira et al. (2005) trabalhando com dois genótipos de sorgo, os quais verificaram redução significativa no teor de proteína bruta em resposta ao aumento da salinidade.

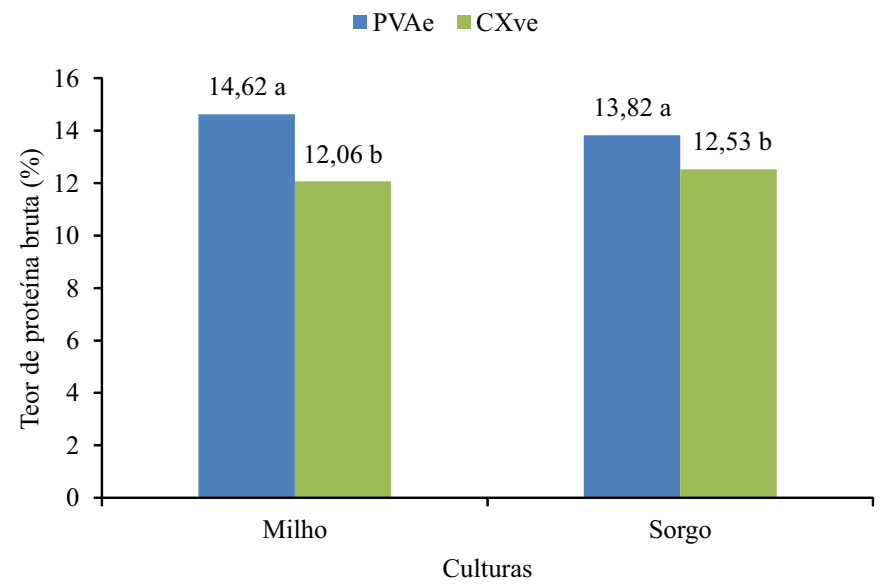

Valores médias seguidas por letras distintas, para cada cultura, diferem estatisticamente pelo teste de Tukey a $5 \%$ de probabilidade

Figura 2. Teores de proteína bruta nas culturas de milho e do sorgo cultivados em dois tipos de solo 
Em contrapartida, Oliveira et al. (2006) avaliaram a resposta de genótipos de sorgo ao estresse salino e observaram respostas variadas entre os genótipos, e que de forma geral, o teor de proteínas aumentou proporcionalmente ao teor de sal no meio de cultivo.

O teores médios de proteína observados neste trabalho são maiores que os observados por Gomes et al. (2006), os quais trabalhando com 11 genótipos de sorgo nas condições climáticas do Ceará, verificaram teores de proteína no tecido foliar variando de 4,12 a 8,36\%, com avaliação realizada aos 120 dias.

Além da variabilidade genética e condições ambientais, $\mathrm{o}$ maior teor de proteína observado no presente trabalho, em confronto com os obtidos por Gomes et al. (2006), pode está relacionado a idade da planta, pois plantas mais velhas podem apresentar menor teor de proteína devido ao efeito da diluição, reduzindo de acordo com o desenvolvimento da cultura (Vale \& Azevedo, 2013).

Em suma, os resultados encontrados neste estudo mostraram que o uso de água com salinidade superior a $2,75 \mathrm{dS} \mathrm{m}^{-1}$ reduz significativamente a produção de biomassa em ambas as culturas, porém, não altera o teor protéico da forragem. Neste contexto, analisando as perdas relativas de massa seca para o milho e o sorgo (média dos dois solos), verificaram-se reduções de 21,6 e $22,3 \%$, respectivamente. Considerando que para a obtenção da água com salinidade de $2,75 \mathrm{dS} \mathrm{m} \mathrm{m}^{-1}$, foi utilizado $56,5 \%$ de água de alta salinidade, ocorreu uma economia de $43,3 \%$ da água de boa qualidade, a qual poderá ser disponibilizada para outros fins, como para o consumo humano, e economia com os gastos provenientes da alimentação de caprinos e ovinos, melhorando na qualidade de vida da população.

\section{Conclusões}

1. A resposta das culturas à salinidade é dependente das características físicas do solo, sendo mais tolerantes em solo com menor teor de argila.

2. A mistura de águas salinas possibilita a produção satisfatória de forragem sem reduzir o teor protéico.

3. A mistura de águas até se obter condutividade elétrica de $2,75 \mathrm{dS} \mathrm{m}^{-1}$ possibilita economia de $43,3 \%$ na água de boa qualidade, com perda de aproximadamente $22 \%$ na produção de biomassa.

\section{Literatura Citada}

Aquino, A. J. S.; Lacerda, C. F; Gomes-Filho, E. Crescimento, partição de matéria seca e retenção de $\mathrm{Na}^{+}, \mathrm{K}^{+}$e $\mathrm{Cl}^{-}$em dois genótipos de sorgo irrigados com águas salinas. Revista Brasileira de Ciência do Solo, v.31, p.961-971, 2007

Carmo Filho, F. do; Oliveira, O. F. de. Mossoró: Um município do semi-árido: caracterização climática e aspecto florístico. Mossoró: ESAM, 1989. 62p. Coleção Mossoroense, 672, Série B

Cecchi, H. M. Fundamentos teóricos e práticos em análise de alimentos. 2.ed. Campinas: UNICAMP, 2003. 207p.
Coelho, D. S.; Simões, W. L.; Mendes, A. M. S.; Dantas, B. F.; Rodrigues, J. A. S.; Souza, M. A. Germinação e crescimento inicial de variedades de sorgo forrageiro submetidas ao estresse salino. Revista Brasileira de Engenharia Agrícola e Ambiental, v.18, p.25-30, 2014.

Feijão, A. R.; Silva, J. C. B.; Marques, E. C.; Prisco, J. T.; GomesFilho, E. Efeito da nutrição de nitrato na tolerância de plantas de sorgo sudão à salinidade. Revista Ciência Agronômica, v.42, p.675-683, 2011.

Freire, M. B. G. S.; Ruiz, H. A.; Ribeiro, M. R.; Ferreira, P. A.; Alvarez V., V. H.; Freire, F. J. Estimativa do risco de sodificação de solos de Pernambuco pelo uso de águas salinas. Revista Brasileira de Engenharia Agrícola e Ambiental, v.7, p.227-232, 2003.

Gomes, S. O.; Pitombeira, J. B.; Neiva, J. N. M.; Cândido. M. J. D. Comportamento agronômico e composição químicobromatológico de cultivares de sorgo forrageiro no Estado do Ceará. Revista Ciência Agronômica, v.37, p.221-227, 2006.

Lacerda, C. F. Efeitos da salinidade no desenvolvimento e composição mineral do feijão-de-corda (Vigna unguiculata(1.) walp.) e utilização do $\mathrm{Ca}^{2+}$ como meio para minorar tais efeitos. Fortaleza: Universidade Federal do Ceará, 2010. Dissertação Mestrado

Lacerda, C. F; Morais, H. M. M.; Prisco, J. T.; Bezerra, M. A. Interação entre salinidade e fósforo em plantas de sorgo forrageiro. Revista Ciência Agronômica, v.37, p.258-263, 2006.

Lima, M. A.; Castro, V. F.; Vidal, J. B.; Enéas-Filho, J. Aplicação de silício em milho e feijão-de-corda sob estresse salino. Revista Ciência Agronômica, v.42, p.398-403, 2011.

Medeiros, J. F.; Lisboa, R. A.; Oliveira, M. Silva Júnior, M. J.; Alves, L. P. Caracterização das águas subterrâneas usadas para irrigação na área produtora de melão da Chapada do Apodi. Revista Brasileira de Engenharia Agrícola e Ambiental, v.7, p.469-472, 2003.

Mendes, A. M. S.; Santos, E. E. F.; Silvam, D. J.; Martinez, E. A.; Dourado, D. L.; Oliveira, J. M.; Santos, N. T. dos. Crescimento e acúmulo de nutrientes em plantas de Sorgum bicolor L. Moench sob irrigação com águas de diferentes concentrações salinas. In: Reunião Brasileira de Manejo e Conservação do Solo e da Água, 17. 2008, Rio de Janeiro. Rio de Janeiro: SBCS: Embrapa Solos: Embrapa Agrobiologia, 2008. CD-Rom. Embrapa Solos. Documentos, 101

Morais Neto, L. B. Avaliação temporal do acúmulo de fitomassa e trocas gasosas do capim-canarana em função da salinidade da água de irrigação. Fortaleza: Universidade Federal do Ceará, 2009. 74p. Dissertação Mestrado

Munns, R.; Tester, M. Mechanisms of salinity tolerance. The Annual Review of Plant Biology, v.59, p.651-681, 2008

Oliveira, L. A. A.; Barreto, L. P.; Bezerra Neto, E.; Santos, M. V. F.; Costa, J. C. A. Solutos orgânicos em genótipos de sorgo forrageiro sob estresse salino. Pesquisa Agropecuária Brasileira, v.41, p.31-35, 2006.

Ribeiro Júnior, J. I. Análises estatísticas no SAEG (Sistema para análises estatísticas). Viçosa: Universidade Federal de Viçosa, 2001. 301p.

SETESB, Companhia Ambiental do Estado de São Paulo. <http:// www.cetesb.sp.gov.br/agua/\%C3\%81 guas-Superficiais/37O-Problema-da-Escassez-de-\%C3\%81gua--no-Mundo>. 3 Ago. 2013. 
Silva, M. O.; Freire, M. B. G. S.; Mendes, A. M. S.; Freire, F. J.; Sousa, C. E. S.; Góes, G. B. Crescimento de meloeiro e acúmulo de nutrientes na planta sob irrigação com águas salinas. Revista Brasileira de Engenharia Agrícola e Ambiental, v.12, p.593-605, 2008.

Sousa, G. G.; Marinho, A. B.; Albuquerque, A. H. P.; Viana, T. V. A.; Azevedo, B. M. Crescimento inicial do milho sob diferentes concentrações de biofertilizante bovino irrigado com águas salinas. Revista Ciência Agronômica, v. 43, p. 237-245, 2012.
Taiz, L.; Zeiger, E. Fisiologia vegetal. 4. ed. Porto Alegre: Artmed, 2009. 819p.

Vale, M. B.; Azevedo, P. V. Avaliação da produtividade e qualidade do capim elefante e do sorgo irrigados com água do lençol freático e do rejeito do dessalinizador. Holos, v. 29, p.181-195, 2013.

Vieira, M. R.; Lacerda, C. F.; Cândido, M. J. D.; Carvalho, P. L.; Costa, R. N. T.; Tabosa, J. N. Produtividade e qualidade da forragem de sorgo irrigado com águas salinas. Revista Brasileira de Engenharia Agrícola e Ambiental, v.9, (Suplemento), p.42-46, 2005. 